\title{
Electrophysiological studies in diabetic neuropathy
}

\author{
ALBERT LAMONTAGNE 1 AND FRITZ BUCHTHAL \\ From the Laboratory of Clinical Neurophysiology, University Hospital, and the Institute \\ of Neurophysiology, University of Copenhagen, Denmark
}

SUMMARY In 30 patients with diabetic neuropathy sensory potentials in the median nerve, motor conduction in the lateral popliteal and median nerves, and electromyographic findings in distal and proximal muscles were compared with the severity of symptoms and signs. All patients had abnormalities in at least one of the electrophysiological parameters. The sensory potentials were the most sensitive indicator of subclinical involvement; abnormalities were found in 24 patients, 12 of whom had no sensory symptoms or signs and five of whom had no other clinical or electrophysiological evidence of neuropathy in the upper extremities. This indicates that sensory nerve fibres may be affected before motor. The next most sensitive parameter was the presence of fibrillation potentials, found in more than half the distal muscles examined. Slowing in motor conduction in the lateral popliteal nerve was the only electrophysiological change correlated to the severity of the neuropathy, and no other electrophysiological parameter was correlated to the duration or the severity of the neuropathy or the diabetes. An onset of neuropathy before or simultaneously with the manifestations of the diabetes, as well as the frequent occurrence of asymptomatic changes in sensory con duction, support the evidence at hand that the neuropathy develops concomitantly with and as a $\frac{P}{p}$ integral part of the metabolic disturbance rather than as a consequence of the vascular complications of diabetes. Of three patients with clinical signs or symptoms of a diabetic amyotrophy, two has asymptomatic electrophysiological abnormalities in distal nerves and muscles, consistent wit widespread involvement of the peripheral nerves. The third patient had electromyographic change in the medial vastus muscles suggestive of a myopathy. Motor and sensory conduction in distal anê proximal nerves were normal.

Previous studies of electrophysiological changes in diabetic neuropathy have dealt with fibrillation potentials, polyphasic potentials, or conduction velocity in motor and, in a few instances, mixed and distal sensory nerves (Downie and Newell, 1961; Lawrence and Locke, 1961; Mulder, Lambert, Bastron, and Sprague, 1961; Skillman, Johnson, Hamur, and Driskill, 1961; Gilliatt and Willison, 1962; Wiesendanger and Bischoff, 1962; Fagerberg, Petersén, Steg, and Wilhelmsen, 1963; Mayer, 1963). Electrophysiological parameters in the same patient have not been compared and there are few studies of sensory conduction and none of conduction along the whole nerve.

The aim of this study, then, was to investigate in patients with diabetes mellitus the different electrophysiological parameters, to see how they correlated with clinical findings, and to look for electrophysio-

${ }^{2}$ Fellow of the Canadian Medical Research Council. logical abnormalities in the upper extremities before they had become clinically involved.

\section{MATERIAL AND METHODS}

PATIENTS Of the 30 patients examined, half were consecutively referred to the University Hospital for electrophysiological study, the others were from a clinic for diabetics (Hvidøre Hospital). The patients had been hospitalized because of their diabetes mellitus and had signs or symptoms suggestive of neuropathy. Their mean age was 50 years, 23 were 40 to 60 years old, three were 29 to 31 years old, and four were 61 to 67 years old. The diabetes began in maturity ( $>40$ years) in 16 patients, and was of the so-called juvenile-onset type in 14 patients (onset at 40 years or less). The neurological examination at the time of the electrophysiological study included quantitation of the vibratory threshold at the distal phalanx of the big toe and of the index finger by means of an electrically driven vibrator (Jersild and Lauritzen, 1967), and of the threshold for electrical current pulses when stimulating digits I, II, and III (Buchthal and 
Rosenfalck, 1966a). The degree of neuropathy was evaluated according to the scale of Table 1. Twelve patients had a moderate to severe involvement $(\geqq 10$ points) and 18 a mild involvement ( $<10$ points). The patients graded as mild were not inconvenienced by their neuropathy, except one who had severe pain in the thighs as the main symptom. Four patients had no complaints. They were included because of absent tendon reflexes (two patients), because of severe wasting of the intrinsic muscles of the hands (one patient), and because of an increased vibratory threshold (one patient). Among the patients with a moderate to severe neuropathy, three were inconvenienced neither by pain nor by weakness in distal or proximal muscles. Achilles or patellar reflexes or both were absent in 27 patients; deep tendon reflexes in the arms were absent in addition in a further 21 . Twenty patients had pain or dysaesthesiae as their main symptom and only six complained of weakness. The symptoms or signs were chiefly localized to the legs except in four patients who mainly had paraesthesiae in the hands or wasting of the intrinsic hand muscles. Symptoms and signs were localized to the one median nerve in two patients and to both ulnar nerves in one patient. The average grading gave nine points for the lower extremities and three points for the upper extremities (Table 1). Ten patients had weakness and pain in the thighs, as the sole complaint in three of them, consistent with a diabetic amyotrophy (Garland, 1955).

Diabetes mellitus had been present a few months to 35 years; the neuropathy had lasted from a few months to
10 years, and neither its duration nor severity was related to the duration of the diabetes $(P>\mathbf{0} \cdot \mathbf{1})$. In six patients, the neurological disturbances preceded or coincided with the diagnosis of diabetes. Patients with a severe neuropathy had had their symptoms for longer than patients with mild involvement and severe metabolic or general impairment was associated with neuropathy of longer duration than mild diabetes $(\mathrm{P}<0.05)$.

\section{ELECTROPHYSIOLOGICAL METHODS}

1 ELECTROMYOGRAPHY A distal muscle of the upper and lower extremities and the $m$. quadriceps femoris were examined (in all 111 muscles). The action potentials were recorded by concentric needle electrodes and the following electromyographic parameters were studied:

$\mathrm{i}$ The number of sites within a muscle with fibrillation potentials or positive sharp waves. Their occurrence in two or more sites indicates denervation (Buchthal and Rosenfalck, 1966b).

ii The pattern of the electrical activity during full effort. A pattern of discrete potentials indicates loss of motor units, and absence of activity indicates total denervation.

iii The average duration and amplitude of 25 to 30 different motor unit potentials recorded during weak or moderate effort. Normal values of the same age were taken from Buchthal (1957, Table 4).

iv The incidence of polyphasic potentials (more than four phases). Three polyphasic potentials per 25 motor

TABLE 1

GRADING OF NEUROLOGICAL* AND OTHER DISTURBANCES IN 30 PATIENTS WITH DI ABETIC NEUROPATHY

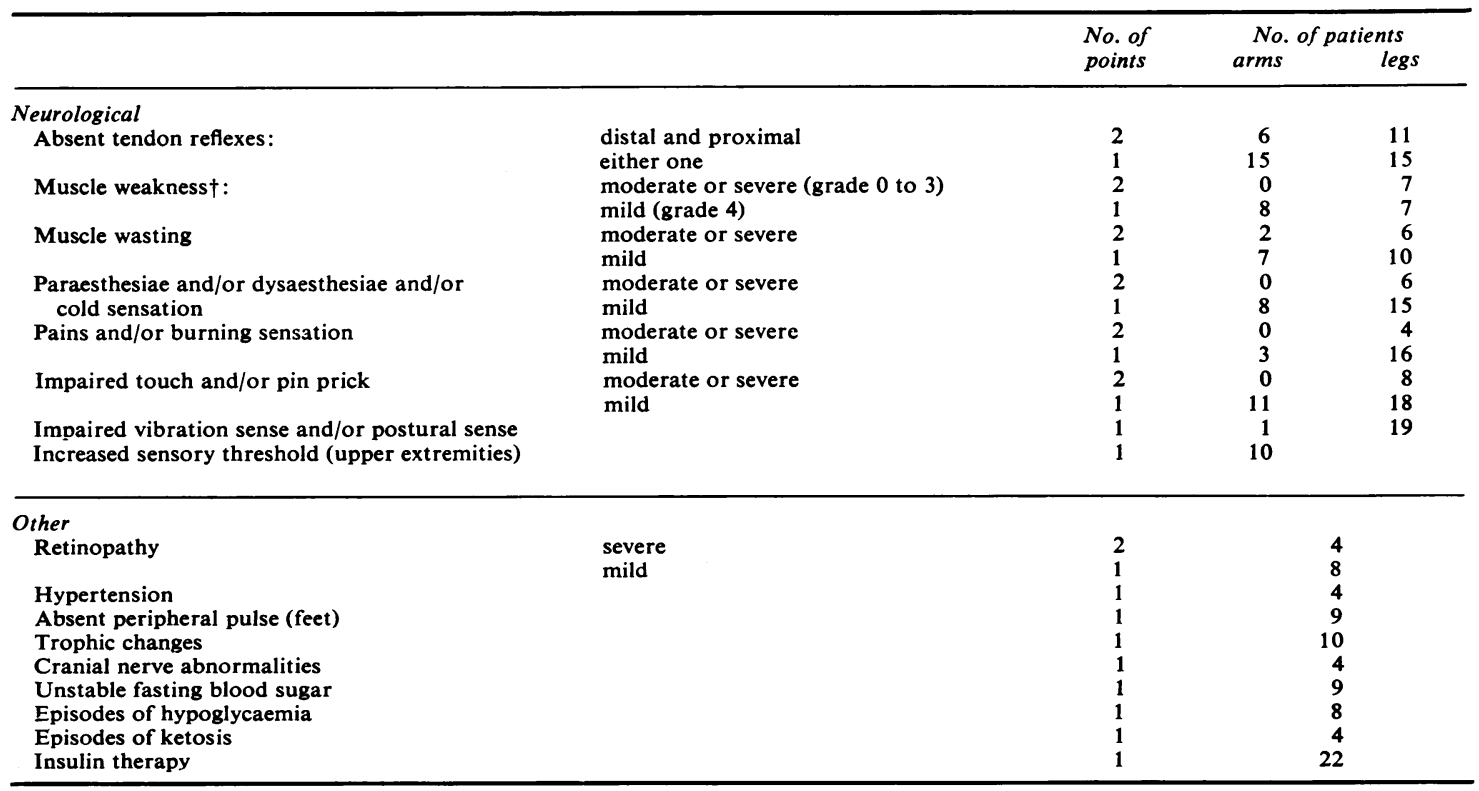

* Graded separately in upper and lower extremities.

† Grading according to the scale given by the Medical Research Council (1943). 
unit potentials occur with a $3 \%$ probability in a rormal subject (Caruso and Buchthal, 1965).

2 MOTOR CONDUCTION AND EVOKED MUSCLE ACTION POTENTIALS Motor conduction was studied in the lateral popliteal and the median nerve. A supramaximal stimulus (0.2 msec, $10 \mathrm{~mA}$, six times the motor threshold) was applied through needle electrodes successively at two sites to the lateral popliteal and at three sites to the median nerve. The evoked potentials were recorded by concentric needle electrodes placed in the end-plate zone at the point of maximum response in the $\mathrm{m}$. extensor digitorum brevis or the $\mathrm{m}$. abductor pollicis.

The following parameters were compared with findings in normal subjects of the same age (Table 5, Trojaborg, 1964; Gassel and Trojaborg, 1965).

i The distal conduction time measured to the onset of the evoked potential and corrected to a standard distance (Slomić, Rosenfalck, and Buchthal, 1968).

ii The peak-to-peak amplitude of the evoked potential.

iii The shape of the potential, characterized as polyphasic when it had five or more phases.

iv The conduction velocity of the fastest fibres.

3 SENSORY CONDUCTION Sensory potentials were recorded in the median nerve at wrist, elbow, and axilla using the method described by Buchthal and Rosenfalck (1966a). The stimulus was supramaximal (20 to $70 \mathrm{~mA}$ ) and the stimulus current was recorded on a separate channel.

The following parameters of the sensory responses were compared with findings in normal subjects (Table 6, Buchthal and Rosenfalck, 1966a).

i The distal conduction velocity. The scale of velocities given below the potentials of Figs. 1, 6 and 8 refers to the different nerve fibres contributing to the potential (cf. reconstructions in Buchthal and Rosenfalck, 1966a).

ii The peak-to-peak amplitude of the potential recorded at wrist.

iii The duration of the potential at wrist, measured from the onset of the initial positive deflection to the intersection of the descending phase of the spike with the base line.

iv The shape of the potential; whether it was regular, irregular or split into more than three phases (Fig. 1).

$v$ The velocity of the fastest fibres between wrist and elbow and between elbow and axilla. When the potentials at elbow and axilla were less than 1 to $2 \mu \mathrm{V}$ the number of stimulated nerve fibres was increased by stimulating digits I, II, and III as described (Buchthal and Rosenfalck, 1966a).

TEMPERATURE The limbs were heated before each examination and maintained at 33 to $35^{\circ} \mathrm{C}$ during the study. This is of special importance in diabetes because of the associated vascular changes (Martin, 1953). The temperature was measured by a thermocouple placed above the sites of stimulation and by a thermoneedle inserted near the nerve and in the muscle.
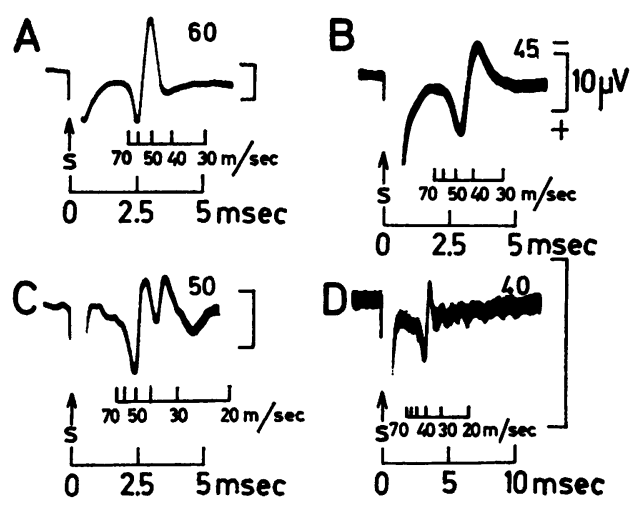

FIG. 1. Samples of different shapes of sensory potentials at wrist evoked by a stimulus of 50 to $60 \mathrm{~mA}$ to digit I in diabetic neuropathies (temperature near the nerve $33^{\circ} \mathrm{C}$ $\left.\pm 0.5^{\circ}\right)$. A: regular, normal duration, B: regular, increased duration (normal motor conduction), C: irregular, D: split. $\mathrm{B}$ and D: 20 superimposed potentials. The figures on the traces give the conduction velocity in $\mathrm{m} / \mathrm{sec}$ between digit I and wrist.

STATISTICAL EVALUATION The significance of differencess

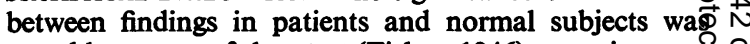
tested by means of the $t$ test (Fisher, 1946) assuming neas $\frac{9}{3}$ normal distributions. When a Gaussian distribution could not properly be used, the normal range was deter mined from the cumulative frequency distribution. Th $t$ test was also applied in the regression analysis to evaluate the significance of possible correlations between clinical and electrophysiological findings.

\section{RESULTS}

To correlate the electrophysiological involvement with the clinical findings, abnormalities in the electromyogram and in motor and sensory conduction were graded according to the scale of Table 2 .

1 ELECTROMYOGRAPHIC FINDINGS Fibrillation potentials, positive sharp waves, or both occurred in two-thirds of the patients, more frequently in distal than in proximal muscles and more frequently in the muscles of the foot than in the muscles of the hand (Table 3). Loss of motor units during full effort occurred in half of the muscles examined, more often in distal muscles of the foot than in other muscles. When the neuropathy had been present for more than a year, severe loss of motor units was twice as common. The average duration of motor unit potentials in distal muscles was increased in half of the extensor digitorum brevis and in one-third of the abductor pollicis brevis muscles examined (Tables 3 , 4, Fig. 2). The incidence of polyphasic potentials was above $12 \%$ in half the muscles examined, as often 1 
TABLE 2

GRADING OF ELECTROPHYSIOLOGICAL FINDINGS

\begin{tabular}{|c|c|c|}
\hline & & $\begin{array}{l}\text { No. of } \\
\text { points }\end{array}$ \\
\hline \multicolumn{3}{|l|}{ Electromyography } \\
\hline Fibrillation potentials and/or & arms & 1 \\
\hline $\begin{array}{l}\text { positive sharp waves } \\
\text { Increased duration of motor }\end{array}$ & $\begin{array}{l}\text { legs } \\
\text { arms }\end{array}$ & $\begin{array}{l}1 \\
1\end{array}$ \\
\hline $\begin{array}{l}\text { Increased duration of motor } \\
\text { unit potentials ( }>20 \%)\end{array}$ & legs & 1 \\
\hline Discrete motor unit activity & arms & 1 \\
\hline Complete denervation & arms & 2 \\
\hline & legs & 2 \\
\hline Incidence of polyphasic & arms & 1 \\
\hline potentials $>12 \%$ & legs & 1 \\
\hline \multicolumn{3}{|c|}{ Lat. popl. nerve, motor conduction } \\
\hline Capitulum fibulae-ankle & $\begin{array}{rr}<41 & >33 \mathrm{~m} / \mathrm{sec} \\
\leqslant 33 & \mathrm{~m} / \mathrm{sec}\end{array}$ & $\begin{array}{l}1 \\
2\end{array}$ \\
\hline $\begin{array}{l}\text { Distal conduction to } \\
\text { m. ext. dig. brevis }\end{array}$ & $\begin{aligned} &>6.2<7.0 \mathrm{msec} \\
& \geqslant 7.0 \quad \mathrm{msec}\end{aligned}$ & $\begin{array}{l}1 \\
2\end{array}$ \\
\hline Amplitude in & $<9.0>5.5 \mathrm{mV}$ & 1 \\
\hline m. ext. dig. brevis & $<5.5 \quad \mathrm{mV}$ & 2 \\
\hline $\begin{array}{l}\text { Polyphasic response in } \\
\text { m. ext. dig. brevis }\end{array}$ & & 1 \\
\hline $\begin{array}{l}\text { Conduction to } \mathrm{m} \text {. tibialis } \\
\text { anterior }\end{array}$ & $>5.0 \mathrm{msec}$ & 1 \\
\hline $\begin{array}{l}\text { Amplitude in } \mathrm{m} . \text { tibialis } \\
\text { anterior }\end{array}$ & $<5.8 \mathrm{mV}$ & 1 \\
\hline Polyphasic response in & & \\
\hline m. tibialis anterior & & 1 \\
\hline \multicolumn{3}{|c|}{ Median nerve, motor conduction } \\
\hline Axilla-wrist & $<51 \mathrm{~m} / \mathrm{sec}$ & 1 \\
\hline $\begin{array}{l}\text { Distal conduction to } \\
\text { m. abd. poll. brevis }\end{array}$ & $\begin{array}{l}>4.7 \mathrm{msec}<5.0 \mathrm{~m} / \mathrm{sec} \\
>5.0 \mathrm{msec}\end{array}$ & $\begin{array}{l}1 \\
2\end{array}$ \\
\hline Amplitude in & $<11.0 \mathrm{mV}>5.0 \mathrm{mV}$ & 1 \\
\hline $\begin{array}{l}\text { m. abd. poll. brevis } \\
\text { Polyphasic response in }\end{array}$ & $<5.0 \mathrm{miV}$ & 2 \\
\hline m. abd. poll. brevis & & 1 \\
\hline \multirow{2}{*}{\multicolumn{3}{|c|}{$\begin{array}{l}\text { Median nerve, sensory conduction } \\
\text { Distal velocity }\end{array}$}} \\
\hline & & \\
\hline digit 1-wrist: & $\begin{array}{l}<41 \mathrm{~m} / \mathrm{sec}>36 \mathrm{~m} / \mathrm{sec} \\
<36 \mathrm{~m} / \mathrm{sec}\end{array}$ & $\begin{array}{l}1 \\
2\end{array}$ \\
\hline digits 2 and 3-wrist & $\begin{array}{l}<47 \mathrm{~m} / \mathrm{sec}>43 \mathrm{~m} / \mathrm{sec} \\
<43 \mathrm{~m} / \mathrm{sec}\end{array}$ & $\begin{array}{l}1 \\
2\end{array}$ \\
\hline \multicolumn{3}{|l|}{ Amplitude } \\
\hline digit 1: & $\begin{array}{l}<25 \mu V(18-30 \mathrm{yr}) \\
<15 \mu \mathrm{V}(40-65 \mathrm{yr})\end{array}$ & 1 \\
\hline digits 2 and 3: & $<12 \mu \mathrm{V}(18-25 \mathrm{yr})$ & 1 \\
\hline \multirow{4}{*}{$\begin{array}{l}\text { Sensory conduction velocity } \\
\text { wrist-elbow } \\
\text { Abnormal shape of } \\
\text { potentials at wrist } \\
\text { Increased duration of } \\
\text { potential at wrist }\end{array}$} & & \\
\hline & $<50 \mathrm{~m} / \mathrm{sec}$ & 1 \\
\hline & & 1 \\
\hline & & 1 \\
\hline
\end{tabular}

in proximal as in distal muscles (Table 3). The polyphasic potentials were often of the 'grouped potential' type, in which the duration of individual spikes was the same as that of the spike in the simple motor unit potential (Fig. 3). Neither the increase in duration of the motor unit potentials nor the increased incidence in polyphasic potentials were related to the duration or the severity of the diabetes or of the neuropathy. All but four of the $\mathbf{3 0}$ patients had abnormalities in at least two of the electromyographic parameters.
TABLE 3

ELECTROMYOGRAPHIC FINDINGS IN 30 PATIENTS WITH DIABETIC NEUROPATHY

\begin{tabular}{lccc}
\hline Muscle & $\begin{array}{c}\text { Extensor } \\
\text { digitorum } \\
\text { brevis } \\
\text { (Per cent of patients) }\end{array}$ & $\begin{array}{c}\text { Quadri- } \\
\text { ceps } \\
\text { femoris }\end{array}$ & $\begin{array}{c}\text { Abductor } \\
\text { pollicis } \\
\text { brevis }\end{array}$ \\
\hline $\begin{array}{l}\text { Fibrillation potentials and/or } \\
\text { positive sharp waves }\end{array}$ & 53 & 17 & 40 \\
$\begin{array}{l}\text { Signs of severe loss of motor } \\
\text { units }\end{array}$ & 63 & 23 & 10 \\
$\begin{array}{l}\text { Increased duration of motor } \\
\text { unit potentials }(>20 \%)\end{array}$ & 50 & 7 & 30 \\
\begin{tabular}{l} 
Polyphasic potentials $(>12 \%)$ \\
\hline
\end{tabular} & 53 & 50 & 43 \\
\hline
\end{tabular}

One of the patients with diabetic amyotrophy had electromyographic changes in both medial vastus muscles suggestive of myopathy: the paretic muscles showed an interference pattern during full effort, the mean action potential duration was decreased by $20 \%$ or more, and the incidence of polyphasic potentials was $30 \%$, the potentials often being of the 'short spike' type.

2 MOTOR CONDUCTION AND EVOKED MUSCLE ACTION POTENTIALS Lateral popliteal nerve The distal conduction time from ankle to the $\mathrm{m}$. extensor digitorum brevis was increased by $18 \%$ and the conduction velocity between capitulum fibulae and ankle was slowed by $28 \%$ (Fig. 4). Distal conduction was slowed in 13 and conduction from the capitulum fibulae to the ankle in 24 of the 30 patients. By contrast, the conduction to a more proximal muscle (m. tibialis anterior) was slowed in only five patients. The amplitude of the evoked response in the extensor digitorum brevis was diminished by $50 \%$ and the shape was polyphasic in nearly half of the patients, consistent with the slowing in conduction and the loss of motor units during full voluntary effort (Table 5). Slowing in motor conduction was the electrophysiological parameter most closely correlated with the severity of the neuropathy $(P<0.01$, Fig. 5). This applied when the slowing was related to symptoms and signs in the lower and in both upper and lower extremities.

Median nerve The distal conduction was slowed by $15 \%$ and the conduction along the arm by $10 \%$ $(P<0.01$, Fig. 4). Distal conduction was slowed in 12 patients-that is, in as many as had slowing in the legs. Slowing between wrist, elbow and axilla occurred in only five patients, more rarely than in the peroneal nerve. The evoked response in the $\mathrm{m}$. abductor pollicis brevis was diminished less than the response in the $\mathrm{m}$. extensor digitorum brevis and a polyphasic potential was recorded only in one 


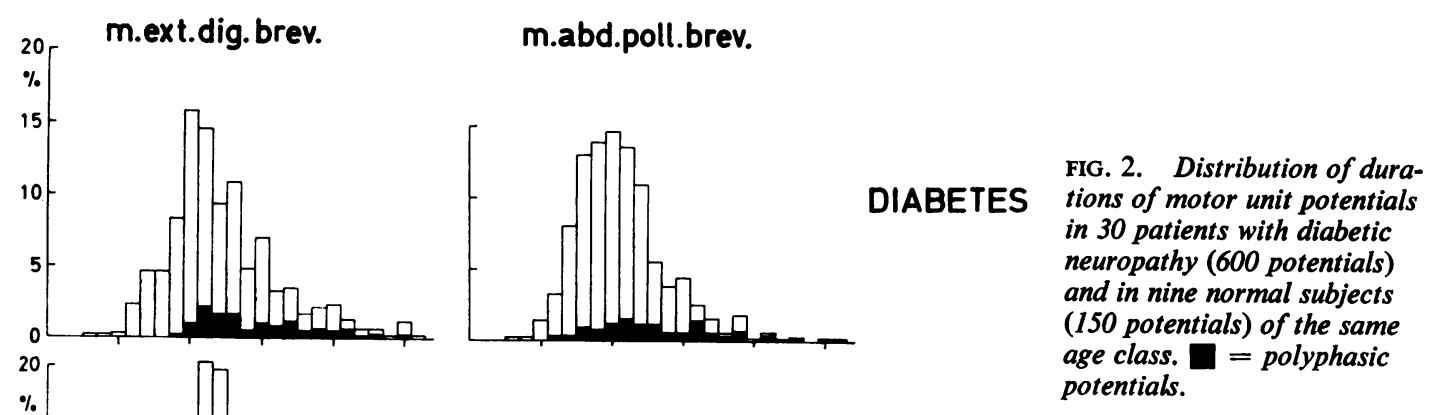

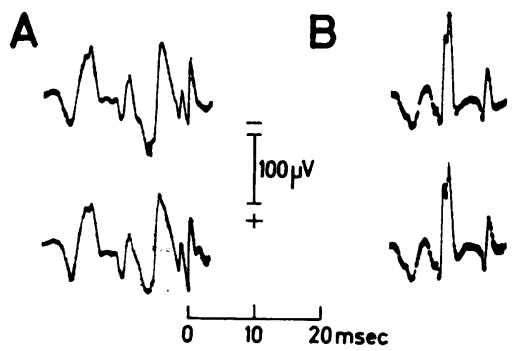

FIG. 3. Samples of 'grouped potentials' A: in $m$. vastus medialis, patient 16, female, 49 years old; proximal symptoms and signs confined to the legs ('diabetic amyotrophy'). B: m. abductor pollicis brevis, patient 15, male, 55 years old; mild distal sensory neuropathy with symptoms and signs confined to the legs. muscle, consistent with the mild weakness and wast- $\rightarrow$ ing of the intrinsic muscles of the hand in most patients. Slowing in conduction occurred in five patients who had no clinical symptoms or signs of motor involvement (Table 5).

3 SENSORY CONDUCTION AND EVOKED SENSORY ACTION POTENTIALS (Fig. 6) Sensory fibres were damaged more frequently than motor, 24 of the 305 patients showing abnormalities in the conduction," amplitude, or shape of the sensory potentials (Table 6 ). Of the 18 patients with a normal distal rate of motor conduction in the median nerve, seven had slowing in the sensory fibres and five others abnormalities of the sensory response. The decrease in distal conduction velocity averaged $13 \%$ (digit I) or $18 \%$ (digits II and III) $(P<0.001)$ and in the velocity along the arm $7 \%(P<0.05)$ (Fig. 7). The average of all sensory potentials recorded at wrist

TABLE 4

DURATION OF MOTOR UNIT POTENTIALS (MSEC) IN DISTAL AND PROXIMAL MUSCLES IN 30 PATIENTS WITH DIABETIC NEUROPATHY AND 19 NORMAL SUBJECTS OF THE SAME AGE CLASS

\begin{tabular}{|c|c|c|c|c|c|c|c|c|c|c|c|}
\hline & \multicolumn{5}{|c|}{ Diabetic patients } & \multicolumn{5}{|c|}{ Normal subjects } & \multirow[b]{2}{*}{$P *$} \\
\hline & No. & $\begin{array}{l}\text { durat. } \\
\text { (msec) }\end{array}$ & $\underset{(m s e c)}{m e}$ & $\begin{array}{l}S D \\
\text { (msec) }\end{array}$ & $\begin{array}{c}\text { polyph. } \\
(\%)\end{array}$ & No. & $\begin{array}{l}\text { durat. } \\
\text { (msec) }\end{array}$ & $\begin{array}{c}m e \\
(m s e c)\end{array}$ & $\begin{array}{c}S D \\
(m s e c)\end{array}$ & $\begin{array}{c}\text { polyph. } \\
(\%)\end{array}$ & \\
\hline $\begin{array}{l}\text { M. ext. dig. brevis } \\
\text { M. abd. poll. brevis } \\
\text { M. rectus femoris } \\
\text { M. vastus medialis }\end{array}$ & $\begin{array}{l}603 \\
705 \\
282 \\
290\end{array}$ & $\begin{array}{l}12 \cdot 9 \\
10 \cdot 7 \\
14 \cdot 6 \\
11 \cdot 7\end{array}$ & $\begin{array}{l}0 \cdot 2 \\
0 \cdot 1 \\
0 \cdot 3 \\
0 \cdot 2\end{array}$ & $\begin{array}{l}3 \cdot 9 \\
3 \cdot 2 \\
4 \cdot 5 \\
4 \cdot 2\end{array}$ & $\begin{array}{l}13 \\
12 \\
10 \\
12\end{array}$ & $\begin{array}{l}178 \\
130 \\
302 \\
152\end{array}$ & $\begin{array}{r}11 \cdot 4 \\
9 \cdot 5 \\
14 \cdot 8 \\
11 \cdot 4\end{array}$ & $\begin{array}{l}0 \cdot 2 \\
0 \cdot 2 \\
0 \cdot 2 \\
0 \cdot 4\end{array}$ & $\begin{array}{l}2 \cdot 9 \\
2 \cdot 8 \\
3 \cdot 8 \\
4 \cdot 7\end{array}$ & $\begin{array}{l}5 \\
4 \\
4 \\
5\end{array}$ & $\begin{array}{l}<0.001 \\
<0.001 \\
>0.5 \\
>0.5\end{array}$ \\
\hline
\end{tabular}

*Significance of difference between the group of patients and of normal subjects. 

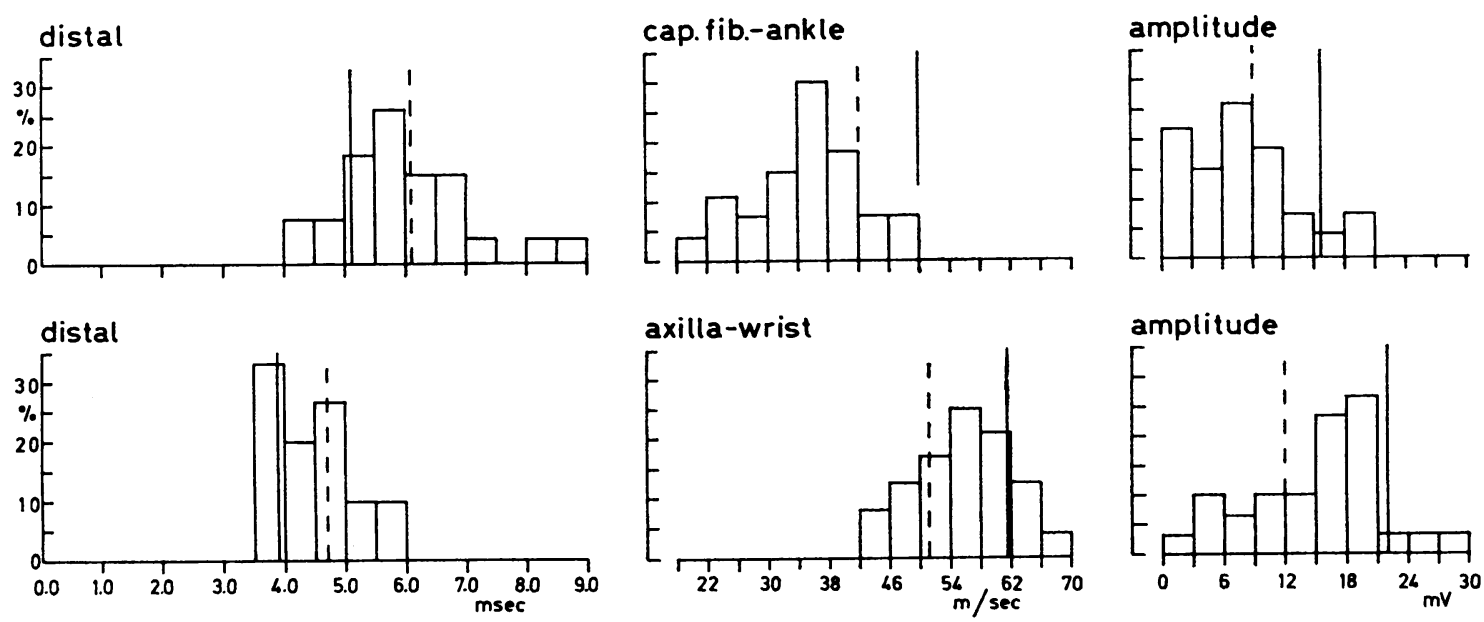

FIG. 4. Distribution of distal motor conductions, motor conduction velocities, and of amplitudes of evoked muscle action potentials in the lateral popliteal (above) and the median nerve (below) in 30 patients with diabetic neuropathy $\left(33^{\circ} \pm\right.$ $\left.0.5^{\circ}\right)$. The full vertical line indicates the mean and the broken line the $95 \%$ lower limit in normal subjects of the same age class.

showed a decrease in amplitude of $50 \%$, indicating a high incidence of sensory involvement even in the absence of its clinical manifestations (Fig. 8A). Thus, of the 18 patients who did not have symptoms of sensory impairment and of five with doubtful complaints, in 17 the conduction, amplitude, or shape of the sensory potentials were abnormal and these abnormalities did not reflect the degree of clinical impairment (Table 6). The decrease in amplitude does not necessarily indicate a loss of sensory fibres, in that slowing as such can account for a decrease in amplitude of 50 to $60 \%$ (Buchthal and Rosenfalck, 1967). This is consistent with the pronounced increase in temporal dispersion of the sensory potentials evidenced by a long duration often associated with irregularities in the shape (Table 6).

An antidromic sensory potential recorded at digit I was absent in all but seven of our patients when the stimulus at wrist was threshold for the motor response. The diagnostic usefulness of this response is limited because it was absent in more than half of the normal subjects of the age class investi-

\section{TABLE 5}

MOTOR CONDUCTION AND EVOKED MUSCLE ACTION POTENTIAL IN 30 PATIENTS WTTH DIABETIC NEUROPATHY AND IN 36 NORMAL SUBJECTS OF THE SAME AGE CLASS (TEMPERATURE NEAR THE NERVE 33 TO $34^{\circ} \mathrm{C}$ )

\begin{tabular}{|c|c|c|c|c|c|c|}
\hline \multirow[b]{2}{*}{$\begin{array}{l}\text { Peroneal nerve } \\
\text { Distal conduction (msec) } \ddagger \text { to } \mathrm{m} \text {. ext. dig. brev. } \\
\text { Amplitude (mV) of the evoked response in } \mathrm{m} \text {. ext. dig. } \\
\text { brev. } \\
\text { Velocity (msec) cap. fib. to ankle } \\
\text { Distal latency (msec) to m. tib. ant. } \\
\text { Amplitude (mV) of the evoked response in } \mathrm{m} \text {. tib. ant. }\end{array}$} & \multicolumn{2}{|c|}{ Diabetic patients } & \multicolumn{2}{|c|}{ Normal subjects } & $\begin{array}{c}P^{*} \\
<0.001\end{array}$ & $\frac{\% \dagger}{47}$ \\
\hline & $\begin{array}{l}6 \cdot 0 \pm 0 \cdot 2 \\
8 \quad \pm 1 \\
36 \pm 1 \cdot 5 \\
4 \cdot 2 \pm 0 \cdot 2 \\
10 \pm 1\end{array}$ & $\begin{array}{l}\text { SD } 5 \cdot 5 \\
\text { SD } 7 \\
\text { SD } 1 \cdot 0 \\
\text { SD } 6\end{array}$ & $\begin{array}{c}16.5 \pm 0.1 \\
50 \pm 0.5 \\
3.8 \pm 0.2 \\
13 \pm 1\end{array}$ & $\begin{array}{l}\text { SD } 5 \\
\text { SD 3.5 } \\
\text { SD 0.5 } \\
\text { SD } 4\end{array}$ & $\begin{array}{l}<0.001 \\
<0.001 \\
<0.001 \\
>0.1 \\
<0.1 \\
>0.05\end{array}$ & $\begin{array}{l}47 \\
63 \\
83 \\
20 \\
23\end{array}$ \\
\hline $\begin{array}{l}\text { Median nerve } \\
\text { Distal conduction (msec) } \ddagger \text { to m. abd. poll. brev. } \\
\text { Amplitude (mV) of the evoked response in m. abd. poll. } \\
\text { brev. } \\
\text { Velocity (msec) elbow-wrist } \\
\text { Velocity (msec) axilla-elbow } \\
\text { Velocity (msec) axilla-wrist }\end{array}$ & $\begin{array}{l}4 \cdot 5 \pm 0 \cdot 1 \\
16 \pm 1 \\
54 \pm 1 \cdot 2 \\
62 \pm 1 \cdot 3 \\
56 \pm 1 \cdot 2\end{array}$ & $\begin{array}{l}\text { SD } 7 \\
\text { SD } 6 \\
\text { SD } 6 \\
\text { SD } 6\end{array}$ & $\begin{array}{c}3.9 \pm 0.1 \\
22 \pm 0.1 \\
57 \pm 1.0 \\
66 \pm 1.4 \\
62 \pm 1.0\end{array}$ & $\begin{array}{l}\text { SD } 6 \\
\text { SD } 5 \\
\text { SD } 8 \\
\text { SD } 5 \cdot 5\end{array}$ & $\begin{aligned} &< 0.001 \\
& 0.1 \\
&<0.05 \\
&<0.005 \\
&>0.001\end{aligned}$ & $\begin{array}{l}20 \\
12 \\
10 \\
17\end{array}$ \\
\hline
\end{tabular}

* Significance of difference between the patients and the normal subjects.

†Per cent of patients with abnormal findings.

$\ddagger$ Corrected to a standard distance. 


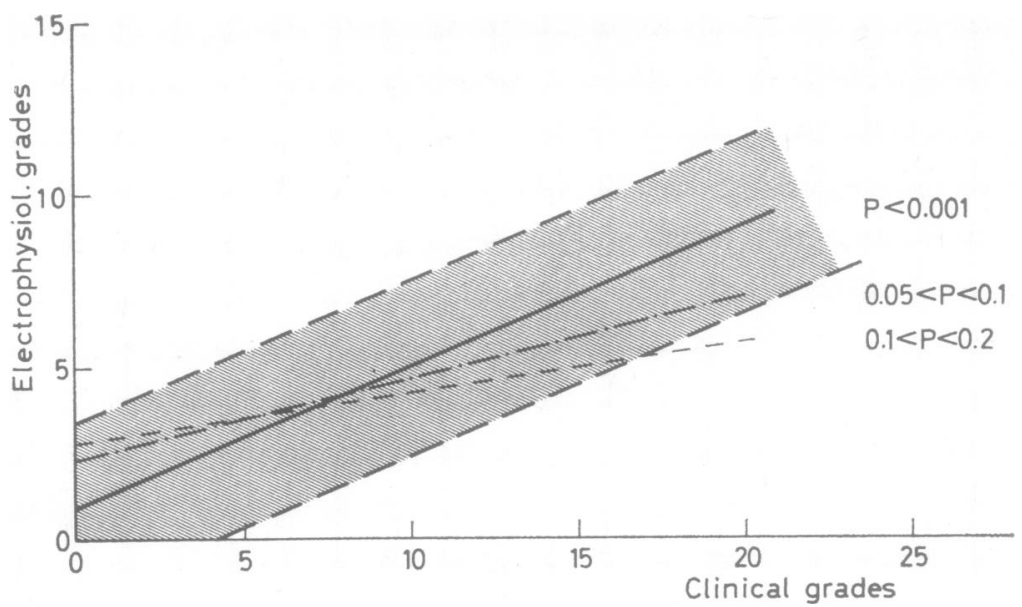

FIG. 5. Correlation between electrophysiological and clinical findings (graded from Tables 1 and 2). Motor conduction, amplitude and shape of the evoked muscle action potential in the lateral popliteal and in the median nerve (full line). The shaded area indicates the range within which two-thirds of the patients were located (regression line \pm standard deviation). Sensory conduction, amplitude and the shape of the evoked response in the median nerve (stippled line). Electromyographic abnormalities in the m.m. extensor digitorum brevis, quadriceps femoris, abductor digitorum brevis (broken line through shaded area). Motor conduction was the only electrophysiological parameter correlated to severity of clinical impairment $(P<0.001)$.

gated in this study. With stronger stimuli potentials from distal muscles often obscured the onset of the antidromic response.

The degree of electrophysiological involvement was the same whether the onset of the diabetes was before (14 patients) or after the age of 40 years
(16 patients) and whether the diabetes was poorle (seven patients) or well controlled ( 23 patients).

DISCUSSION

Several workers have demonstrated subclinical

TABLE 6

CONDUCTION, AMPLITUDE, AND SHAPE OF SENSORY ACTION POTENTIALS IN 30 PATIENTS WITH DIABETIC NEUROPATHY AND IN 11 NORMAL SUBJECTS OF THE SAME AGE CLASS (TEMPERATURE NEAR THE NERVE $33^{\circ} \mathrm{C} \pm 0.5^{\circ} ; 35^{\circ} \mathrm{C} \pm 0.4^{\circ}$ )

\begin{tabular}{|c|c|c|c|c|c|c|}
\hline \multirow[b]{2}{*}{ Distal conduction velocity $(\mathrm{m} / \mathrm{sec})$ digit I } & \multicolumn{2}{|c|}{$\begin{array}{r}\text { Diabetic patients } \\
S D\end{array}$} & \multicolumn{2}{|c|}{$\begin{array}{r}\text { Normal subjects } \\
S D\end{array}$} & \multirow{2}{*}{$\begin{array}{c}P \\
<0.005 \\
>0.001\end{array}$} & \multirow{2}{*}{$\frac{\%}{63}$} \\
\hline & $42 \pm 1 \cdot 0$ & $5 \cdot 6$ & $48 \pm 1 \cdot 4$ & $4 \cdot 5$ & & \\
\hline \multirow[t]{2}{*}{$\begin{array}{l}\text { Distal conduction velocity }(\mathrm{m} / \mathrm{sec}) \text { digits II and III } \\
\text { Amplitude }(\mu \mathrm{V}) \text { wrist stim. dig. I } \\
\text { Amplitude }(\mu \mathrm{V}) \text { wrist stim. dig. II and III } \\
\text { Vel. (m/sec) wrist-elbow } \\
\text { Vel. }(\mathrm{m} / \mathrm{sec}) \text { elbow-axilla } \\
\text { Vel. }(\mathrm{m} / \mathrm{sec}) \text { wrist-axilla }\end{array}$} & $\begin{aligned} 47 & \pm 0 \cdot 8 \\
13 & \pm 1 \cdot 5 \\
6 & \pm 0 \cdot 6 \\
52 & \pm 1 \\
68 & \pm 1 \cdot 6 \\
58 & \pm 1 \cdot 2\end{aligned}$ & $\begin{array}{l}5 \cdot 8 \\
7 \cdot 5 \\
4 \\
5 \\
7 \\
5 \cdot 5\end{array}$ & $\begin{array}{l}57 \pm 0.9 \\
25 \pm 3 \\
11 \cdot 5 \pm 1 \cdot 0 \\
56 \pm 0.8 \\
68 \pm 3 \cdot 1 \\
60 \pm 1 \cdot 4\end{array}$ & $\begin{array}{c}4 \cdot 1 \\
10 \cdot 5 \\
4 \cdot 5 \\
2 \cdot 5 \\
10 \\
4 \cdot 5\end{array}$ & $\begin{array}{l}<0.001 \\
<0.001 \\
<0.001 \\
<0.05 \\
>0.9 \\
>0.8\end{array}$ & $\begin{array}{l}60 \\
63 \\
63 \\
43 \\
13 \\
17\end{array}$ \\
\hline & \multicolumn{2}{|c|}{ Stimulus to digit } & \multicolumn{2}{|c|}{ Stimulus to digit } & & \\
\hline $\begin{array}{l}\text { Regular potential normal duration } \\
\text { Regular potential increased duration } \\
\text { Irregular potential } \\
\text { Split potential }\end{array}$ & $\begin{array}{c}I \\
(\%) \\
37 \\
13 \\
3 \\
47\end{array}$ & $\begin{array}{c}\text { III } \\
(\%) \\
17 \\
3 \\
10 \\
70\end{array}$ & $\begin{array}{c}I \\
(\%) \\
100 \\
0 \\
0 \\
0\end{array}$ & $\begin{array}{c}\text { III } \\
(\%) \\
91 \\
0 \\
0 \\
9\end{array}$ & & \\
\hline
\end{tabular}

* Number of patients with abnormal findings in per cent of patients examined. 


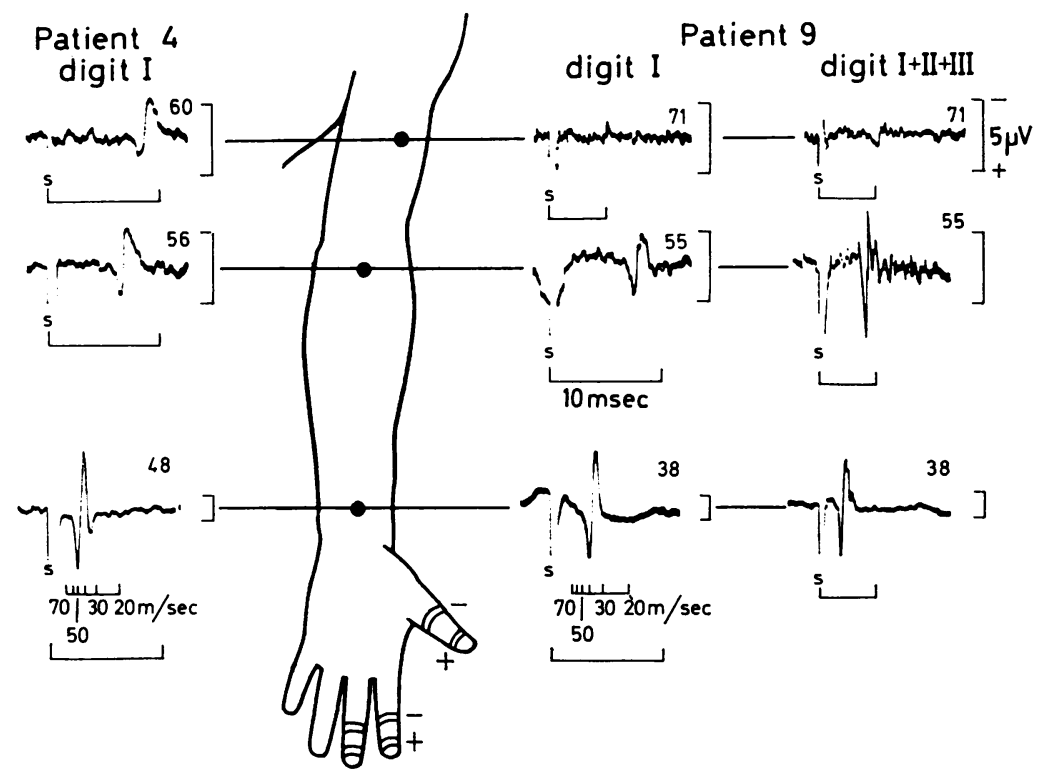

FIG. 6. Sensory potentials in the median nerve at wrist, elbow, and axilla. The figures on the traces give the conduction velocity in $\mathrm{m} / \mathrm{sec}$ between finger and wrist, between wrist and elbow and between elbow and axilla. Left: Stimulus $55 \mathrm{~mA}, 16 \times \mathrm{Ts}^{*}\left(33^{\circ} \mathrm{C}\right)$; patient 4, male, 54 years, diabetes for four years, signs and symptoms of neuropathy for two years with paraesthesiae and pain in feet and calves and questionable sensory impairment in the upper extremities. Sensory and motor conduction were normal in the median nerve. EMG showed fibrillation and polyphasia in the m. abductor pollicis brevis. Distal conduction in the lateral popliteal nerve was slowed. EMG showed loss of motor units, increase in action potential duration, polyphasia and fibrillatios potentials in the m. extensor digitorum brevis. Right: Stimulus $50 \mathrm{~mA}, 7 \times \mathrm{Ts}^{\circ}\left(34^{\circ} \mathrm{C}\right)$; patient 9, female, 29 years old, diabetes for 10 years, and amyotrophy with pain, paraesthesiae, weakness, and wasting in the thighs for five months. No signs or symptoms of sensory or motor impairment in the upper extremities. Distal sensory and motor conduction was slowed in the median nerve. EMG showed polyphasia as the sole abnormality in the $m$. abductor pollicis brevis. Conduction in the lateral popliteal nerve was slowed between capitulum fibulae and ankle. EMG showed loss of motor units and fibrillation potentials in the $m$. extensor digitorum brevis and fibrillation potentials and polyphasia in the m. quadriceps femoris.

*Threshold at which each electrical stimulus was perceived.

involvement of motor nerve fibres in patients with diabetes by comparing motor conduction in groups of patients with motor conduction in normal subjects. These studies concerned patients with or without diabetic neuropathy (Lawrence and Locke, 1961; Mulder et al., 1961; Skillman et al., 1961 ; Fagerberg et al., 1963; Mayer, 1963; Gamstorp, 1964; EegOlofsson and Petersén, 1966) and mixed groups (Gregersen, 1964, 1967). In the individual patient, slowing in motor conduction was often borderline in the non-affected nerves of patients with isolated peripheral nerve lesions (Gilliatt and Willison, 1962). Our findings of abnormalities in sensory action potentials in the median nerve of many patients without corresponding clinical signs made it possible to establish the presence of latent involvement in the individual patient. The $50 \%$ decrease in the sensory potentials and their increased temporal dispersion can be accounted for solely by the slowing in conduction without requiring the assumption of loss of fibres (Buchthal and Rosenfalck, 1967), consistent with the finding of more or less advanced segmental demyelination and remyelination as the predominant histological abnormality (Thomas and Lascelles, 1966, Chopra, Hurwitz, and Montgomery, 1969). In this connection, it was essential that the procedure made it possible to record a sensory potential at wrist in all patients and in most patients also at elbow and axilla; in previous studies, a sensory potential was absent in more than three quarters of the 

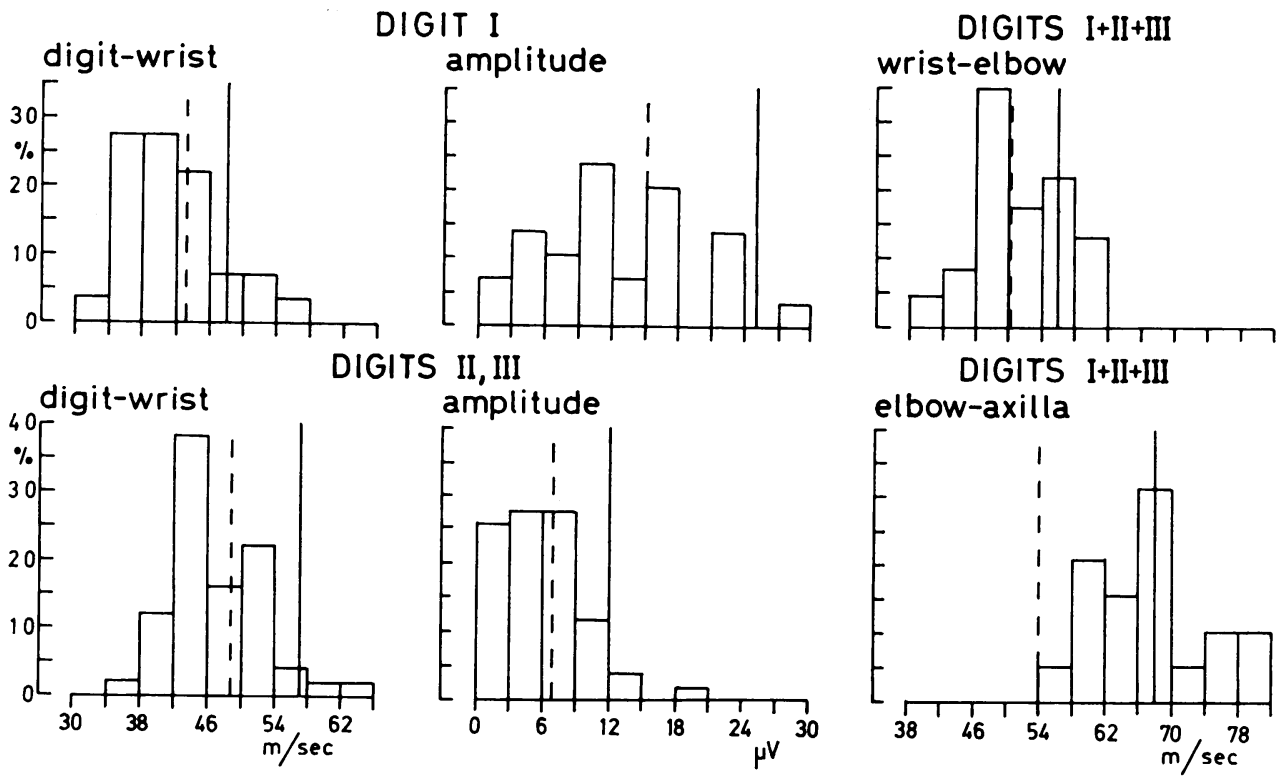

FIG. 7. Distal and proximal conduction velocities and amplitudes of the sensory potentials recorded at wrist in the median nerve of 30 patients with diabetic neuropathy (temperature near the nerve $33^{\circ} \mathrm{C} \pm 0.5^{\circ}$ ). The full vertcial line indicates the mean and the broken line the $95 \%$ lower limit in normal subjects of the same age class.

patients (Downie and Newell, 1961; Wiesendanger and Bischoff, 1962). The subclinical sensory involvement is in keeping with the findings of demyelination in 17 of 26 peripheral nerves which supplied areas without clinical involvement (Dolman, 1963), and with the lack of a correlation between abnormalities in sensory conduction and the severity of the neuropathy. That electrophysiological signs of sensory impairment are likely to appear before changes in motor nerve fibres is indicated by the fact that five of the patients with abnormalities in sensory conduction did not have electrophysiological evidence of the involvement of motor nerve fibres (including fibrillation potentials); and all patients with distal slowing in motor fibres also had abnormalities in sensory conduction.

Fibrillation potentials were the next most sensitive indicator of involvement (Thage, Trojaborg, and Buchthal, 1963). They were seen in three patients without other electrophysiological signs of motor or sensory involvement and in the absence of weakness or wasting. In our patients, the incidence of fibrillation potentials was twice that reported by Wiesendanger and Bischoff (1962) and still higher than that reported by Skillman et al., 1961), probably due to precautions taken to maintain a temperature of 33 to $34^{\circ} \mathrm{C}$ in the muscles. Without heating the intramuscular temperature was at times as low as $25^{\circ} \mathrm{C}$.
The slowing in the lateral popliteal nerve was the electrophysiological parameter most closely related on to the severity of the neuropathy $(P<0.001)$. previous studies, the average slowing in motor cont duction along the median and ulnar nerves has been reported to be as severe as in the lateral popliteal nerve, both in patients with and without clinical signs of neuropathy (Mulder et al., 1961; Lawrence and Locke, 1962; Mayer, 1963; Gamstorp, 1964; Gregersen, 1967). In our patients distal slowing was as pronounced in the upper as in the lower extremities, but in the more proximal segments of the nerves slowing was two to three times greater in the lateral popliteal than in the median nerve. This is consistent with the findings of Skillman et al. (1961) and of Johnson (1962) and with the more pronounced clinical involvement of the legs than of the arms. That slowing in motor conduction in our patients scattered less than in other series of patients (Mayer, 1963; Eeg-Olofsson and Petersén, 1966) may be due to the more accurate definition of the point of stimulation when the stimulus was applied through needle electrodes placed near the nerve. At any rate this may avoid paradoxical findings such as a significant increase in velocity reported in young diabetics.

Even when the clinical signs and symptoms of neuropathy were mild, electrophysiological ab- N normalities were widespread and one or the other 
Median Ulnar
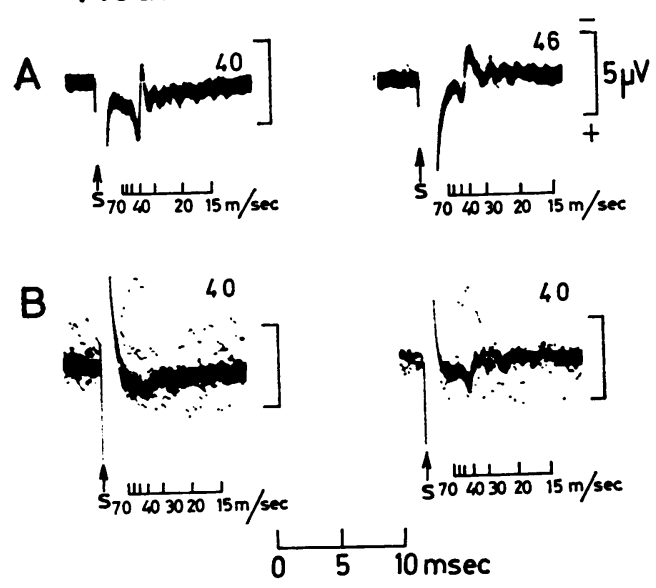

FIG. 8. Sensory potentials at wrist evoked by stimuli to digit I (left) and to digit V (right) in a patient without (A) and in a patient with (B) symptoms and signs of sensory impairment. The figures on the traces give the conduction velocity in $\mathrm{m} / \mathrm{sec}$ between finger and wrist. A: Stimulus $60 \mathrm{~mA}, 7 \times T s^{*}\left(35^{\circ} \mathrm{C}\right)$, patient 29,60 years, with diabetes and neuropathy in the legs for six months without symptoms or signs in the upper extremities. The distal motor conduction in the ulnar nerve was slowed, in the median nerve distal and proximal motor conduction was normal. EMG showed an increased action potential duration and fibrillation potentials in the $m$. abductor pollicis brevis. Conduction was slowed in the lateral popliteal nerve and EMG showed loss of motor units, increased duration and polyphasia in the $m$. extensor digitorum brevis. B: Stimulus $60 \mathrm{~mA}, 7 \times T s^{*}\left(33^{\circ} \mathrm{C}\right)$, patient 19,59 years, with diabetes for 10 years and symptoms and signs of neuropathy in the lower and upper extremities for four years. In the median and ulnar nerve, distal motor conduction was slowed and EMG showed fibrillation potentials and increased action potential duration in the m. abductor pollicis brevis. Conduction in the lateral popliteal nerve was slowed and the EMG showed loss of motor units in the $m$. extensor digitorum brevis and $m$. quadriceps femoris.

*For definition see Fig. 7.

occurred in all patients examined. Two patients with diabetic amyotrophy had fibrillation potentials in the muscles of the thigh and a slowing in conduction of the femoral nerve compatible with a motor neuropathy in the femoral nerve (Calverley and Mulder, 1960). In addition there was evidence of involvement of distal nerves and muscles with slowing of conduction in the lateral popliteal and the median nerves in agreement with findings in diabetic amyotrophy by Gilliatt and Willison (1962) and Chopra and Hurwitz (1968). The third patient was the only ' one with electromyograpoic abnormalities in the medial vastus muscles suggestive of myopathy such as has been described in biopsies as atrophic muscle fibres scattered randomly among normal fibres (Bischoff, 1959; Garland, 1961; Locke, Lawrence, and Legg, 1963; Coërs, 1966). In this patient, motor conduction in the femoral and lateral popliteal nerves as well as sensory conduction in the median nerve was normal, but there were fibrillation potentials in several sites of the abductor pollicis brevis muscle. Except for these patients, electrophysiological studies confirmed the clinical experience of distal rather than proximal involvement. Only the incidence of polyphasic potentials was increased as often in the quadriceps femoris muscle as in distal muscles, indicating proximal damage to motor units at a stage of the disease when there was no proximal weakness or wasting. The polyphasic potentials were more often of the 'grouped potential' type than with 'short spike' duration. 'Grouped potentials' occur in paresis secondary to involvement of the peripheral nerves (Buchthal and Pinelli, 1953). The increased temporal dispersion in these potentials is due either to slowing in immature distal nerve fibres or in partially demyelinated fibres. In none of the muscles studied was there electrophysiological evidence compatible with anterior horn cell involvement as described by Wiesendanger and Bischoff (1962).

Neuropathy can occur early in the course of diabetes, even before there is other evidence of disturbance in carbohydrate metabolism (Ellenberg, 1958). In fact, in six of our patients symptoms or signs of neuropathy appeared before or about at the time when the metabolic disturbance was diagnosed. In view of the frequent asymptomatic sensory involvement in the median nerve one might expect similar pre-clinical changes in sensory conduction in the lateral popliteal nerve. The diabetic neuropathy may then be a direct consequence or an integral part of the metabolic defect (Ellenberg, 1964) rather than a secondary effect of the vascular disturbance. In fact, lesions have not been found in the interfascicular and intrafascicular branches of the vasa nervorum in diabetic neuropathy (Greenbaum, Richardson, Salmon, and Urich, 1964; Greenbaum, 1964) nor were there electrophysiological abnormalities in non-diabetic patients suffering from peripheral vascular disease (Chopra and Hurwitz, 1968). That groups of patients with or without clinical neuropathy exhibited a greater slowing in motor conduction when the diabetes had lasted for more than five years (Gregersen, 1964, 1967) does not invalidate this idea. It may merely reflect the increased probability of finding more severe manifestations of a neuropathy when the diabetes has lasted longer. This interpretation is in keeping with the absence of a relation between the clinical duration of the diabetes 
and the impairment in motor conduction and other electrophysiological abnormalities in the individual patient.

Our thanks are due to Dr. M. Jersild, medical director of Hvidøre Hospital, Copenhagen; to the staff of the neuromedical department of the University Hospital who allowed us to study patients under their care; and to Drs. A. and P. Rosenfalck for their help in the preparation of the manuscript. The work was supported by the Muscular Dystrophy Associations of America, Inc.

\section{REFERENCES}

Bischoff, A. (1959). Zur diabetischen Amyotrophie (Neuromyopathie). Schweiz. med. Wschr., 89, 519-525.

Buchthal, F. (1957). An Introduction to Electromyography, pp. 43-48. Gyldendal: Copenhagen.

Buchthal, F., and Pinelli, P. (1953). Action potentials in muscular atrophy of neurogenic origin. Neurology (Minneap.), 3, 591-603.

Buchthal, F., and Rosenfalck, A. (1966a). Evoked action potentials and conduction velocity in human sensory nerves. Brain Res., 3, 1-122.

Buchthal, F., and Rosenfalck, P. (1966b). Spontaneous electrical activity of human muscle. Electroenceph. clin. Neurophysiol., 20, 321-336.

Buchthal, F., and Rosenfalck, A. (1968). Causes of abnormal sensory potentials in neuropathy Electroenceph. clin. Neurophysiol., 25, 405-406.

Calverley, J. R., and Mulder, D. W. (1960). Femoral neuropathy. Neurology (Minneap.), 10, 963-967.

Caruso, G., and Buchthal, F. (1965). Refractory period of muscle and electromyographic findings in relatives of patients with muscular dystrophy. Brain, 88, 29-50.

Chopra, J. S., and Hurwitz, L. J. (1968). Femoral nerve conduction in diabetes and chronic occlusive vascular disease. J. Neurol. Neurosurg. Psychiat., 31, 28-33.

Chopra, J. S., Hurwitz, L. J., and Montgomery, D. A. D. (1969). The pathogenesis of sural nerve changes in diabetes mellitus. Brain, 92, 391-418.

Coêrs, C. (1966). Altération neuro-musculaire dans le diabète. C.R. Congr. Psychiat. Neurol. langue française, Grenoble, pp. 685-693.

Dolman, C. L. (1963). The morbid anatomy of diabetic neuropathy. Neurology (Minneap.), 13, 135-142.

Downie, A. W., and Newell, D. J. (1961). Sensory nerve conduction in patients with diabetes mellitus and controls. Neurology (Minneap.), 11, 876-882.

Eeg-Olofsson, O., and Petersén, I. (1966). Childhood diabetic neuropathy, a clinical and neurophysiological study. Acta padiat. (Uppsala), 55, 163-176.

Ellenberg, M. (1958). Diabetic neuropathy presenting as the initial clinical manifestation of diabetes. Ann. int. Med., 49, 620-631.

Ellenberg, M. (1964). Clinical concept of prediabetes. N.Y. St. J. Med., 64, 2885-2891.

Fagerberg, S.-E., Petersén, I., Steg, G., and Wilhelmsen, L. (1963). Motor disturbances in diabetes mellitus. A clinical study using electromyography and nerve conduction velocity determination. Acta med. scand., 174, 711-716.

Fisher, R. A. (1946). Statistical Methods for Research Workers, 10th ed., pp. 354. Oliver and Boyd: Edinburgh.
Gamstorp, I. (1964). Conduction velocity of peripheral motor nerves in mental retardation, diabetes and $\mathbb{D}$ various neurological diseases in childhood. Acta padiat. (Uppsala), 53, 408-416.

Garland, H. T. (1955). Diabetic amyotrophy. Brit. med. J., 2, $1287-1290$.

Garland, H. T. (1961). Diabetic amyotrophy. Brit. J. clin. Tे Pract., 15, 9-15.

Gassel, M. M., and Trojaborg, W. (1965). Clinical and $\stackrel{\rho}{\underline{\partial}}$ electrophysiological study of the pattern of conduction times in the distribution of the sciatic nerve. $J \geq$ Neurol. Neurosurg. Psychiat., 27, 351-357.

Gilliatt, R. W., and Willison, R. G. (1962). Peripheral nerve $\overrightarrow{\overline{\overrightarrow{ }}}$ conduction in diabetic neuropathy. J. Neurol. Neuro-surg. Psychiat., 25, 11-18.

Greenbaum, D. (1964). Observations on the homogeneous nature and pathogenesis of diabetic neuropathy. $\overline{\bar{\sigma}}$ Brain, 87, 215-232.

Greenbaum, D., Richardson, P. C., Salmon, M. V., and® Urich, H. (1964). Pathological observations on six cases of diabetic neuropathy. Brain, 87, 201-214.

Gregersen, G. (1964). Motor-nerve function and duration of diabetes. Lancet, $2,733$.

Gregersen, G. (1967). Diabetic neuropathy: Influence of age, $\vec{\omega}$ sex, metabolic control and duration of diabetes on? motor conduction velocity. Neurology (Minneap.), 17, 972-980.

Jersild, M., and Lauritzen, E. (1967). Sensibilité vibratoirecu chez les diabétiques. Le Diabète, 6, 237-241.

Johnson, E. W. (1962). Motor nerve conduction velocity In:diabetes. Arch. Neurol. (Chic.), 7, 365.

Lawrence, D. G., and Locke, S. (1961). Motor nerve côp- $\vec{N}$

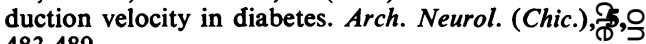
483-489.

Lawrence, D. G., and Locke, S. (1962). Motor nerve cerduction velocity in diabetes. Arch. Neurol. (Chic.) 7, 365-367.

Locke, S., Lawrence, D. G., and Legg, M. A. (1963). Diabefices amyotrophy. Amer.J. Med., 34, 775-785.

Martin, M. M. (1953). Diabetic neuropathy, a clinical stưfy of 150 cases. Brain, 76, 594-624.

Mayer, R. F. (1963). Nerve conduction studies in man Neurology (Minneap.), 13, 1021-1030.

Medical Research Council (1944). Aids to the Investigation of Peripheral Nerve Injuries. 2nd ed. H.M.S.O.: London.

Mulder, D. W., Lambert, E. H., Bastron, J. A., and Sprague R. G. (1961). The neuropathies associated with diabetes mellitus. A clinical and electromyographice study of 103 unselected diabetic patients. Neurology (Minneap.), 11, 275-284.

Skillman, T. G., Johnson, E. W., Hamwi, G. J., and Driskill? H. F. (1961). Motor nerve conduction velocity in diabetes mellitus. Diabetes, 10, 46-51.

Slomić, A., Rosenfalck, A., and Buchthal, F. (1968). Elec=trical and mechanical responses of normal and5 myasthenic muscle with particular reference to the staircase phenomenon. Brain Res., 10, 1-78.

Thage, O., Trojaborg, W., and Buchthal, F. (1963). Electro myographic findings in polyneuropathy. Neurology? (Minneap.), 13, 273-278.

Thomas, P. K., and Lascelles, R. G. (1966). The pathology of diabetic neuropathy. Quart. J. Med., 35, 489-509은

Trojaborg, W. (1964). Motor nerve conduction velocities in normal subjects with particular reference to the con duction in proximal and distal segments of mediarz. and ulnar nerve. Electroenceph. clin. Neurophysiol., 170 314-321.

Wiesendanger, M., and Bischoff, A. (1962). ElectromyographA ische Verănderungen bei der diabetischen Neuro pathie. Bull. schweiz. Akad. med. Wiss., 17, 233-246. 